\title{
Evaluation of Homogeneity of Binary Blends of Poly(3-hydroxybutyrate) and Poly(L-lactic acid) Studied by Near Infrared Chemical Imaging (NIRCI)
}

\author{
Tsuyoshi Furukawa, $* * *+$ Harumi Sato, $* *$ Hideyuki ShInZawa,** Isao Noda,*** \\ and Shukichi OCHIAI* \\ *S. T. Japan Inc., Hirakata, Osaka 573-0094, Japan \\ **School of Science and Technology and Research Center for Environment Friendly Polymers, \\ Kwansei Gakuin University, Sanda 669-1337, Japan \\ ***The Procter \& Gamble Company, 8611 Beckett Road, West Chester, OH 45069, USA
}

\begin{abstract}
The homogeneity of blends of poly $((R)$-3-hydroxybutyrate) (PHB) and poly(L-lactic acid) (PLLA) was evaluated by the near infrared chemical imaging (NIRCI) technique. NIRCI can nondestructively investigate a sample over a wide field of view within a few minutes to acquire a large number of spatially resolved NIR spectral data. NIRCI may be combined with multivariate analysis not only for qualitative analysis but also for statistically based quantitative analysis. The score images derived from the partial least squares regression (PLSR) analysis directly show that PHB/PLLA blends are highly homogeneous. The standard deviations (STD) of the histograms, indicating the distribution of the score values, show small values for the blends. These results qualitatively and quantitatively show the high level of homogeneity of PHB/PLLA blends. The predictions of the spatially averaged concentrations of the blend components obtained from PLSR results show values similar to the actual contents for the blends. The small errors of the predictions are also explained by STD values.
\end{abstract}

(Received March 6, 2007; Accepted May 31, 2007; Published July 10, 2007)

\section{Introduction}

$\operatorname{Poly}((R)-3$-hydroxybutyrate) (PHB) and poly(L-lactic acid) (PLLA) are well-studied aliphatic biodegradable polymers. PHB synthesized by bacteria is a biodegradable thermoplastic. ${ }^{1-7}$ PHB has received much attention as a environmentally friendly material because of its thermoplasticity coupled with its biodegradability. However, it has been recognized that PHB is often too rigid and stiff for many applications because of the perfectly isotactic structure consisting exclusively of the $R$ configuration. PLLA produced from renewable resources, such as starch, also is a biodegradable and biocompatible thermoplastic. ${ }^{7-11}$ PLLA has already been used in various applications, especially in the medical field, because of its superior biocompatibility. The crystalline structures of PHB and PLLA have been established as orthorhombic systems by means of wide angle X-ray diffraction (WAXD). ${ }^{12-16}$ The thermal behavior of PHB and PLLA have also been investigated by infrared (IR) spectroscopy, differential scanning calorimetry (DSC), and WAXD. ${ }^{17-22}$

The physical and mechanical properties of PHB and PLLA are not always suitable for practical applications. Several modifications have been proposed to improve their processing and mechanical properties, such as copolymerization and blending with other biodegradable polymers. Compared to copolymerization methods, physical blending is an easier and faster way to manipulate the desired properties of polymeric

$\dagger$ To whom correspondence should be addressed.

E-mail: furukawa@ksc.kwansei.ac.jp materials. Several studies of the miscibility and morphology for PHB/PLLA blends have been published. ${ }^{23-30}$ In our previous studies, the miscibility and dispersibility of PHB/PLLA blends were revealed by IR and Raman microspectroscopy. ${ }^{29,30}$ These studies showed that the PHB component is always crystallized in the blends irrespective of the blend ratio, and that both components are mixed in the nonspherulite parts. However, these studies were carried out in only some localized spots of samples with different morphology by using polarized light microscopy. Thus, the blends were not analyzed in much wider areas encompassing the entire composite material.

Near infrared (NIR) spectroscopy is widely used as a tool for materials characterization. ${ }^{31-34}$ In the NIR region $(800-2500$ $\mathrm{nm}$ ), the overtone and combination bands of the $\mathrm{C}-\mathrm{H}, \mathrm{O}-\mathrm{H}$, and $\mathrm{N}-\mathrm{H}$ stretching and deformation vibrational modes provide highly specific molecular information for species identification. Sample preparation and handling are relatively straightforward for NIR spectroscopy. Multivariate data analysis has also accelerated the application of NIR spectroscopy. ${ }^{35-38}$ Therefore, NIR spectroscopy has often been adopted as a useful probe in studying polymers. For example, the isothermal crystallization kinetics of PHB was investigated by NIR spectroscopy. ${ }^{39}$ An NIR on-line monitoring system has proven to be useful in the quantitative analysis of the molten polyolefin polymers ${ }^{40-43}$ and in the tracking of the transesterification reaction of molten ethylene vinyl acetate (EVA) copolymers. ${ }^{44,45}$

Recently, the NIR chemical imaging (NIRCI) technique has received keen interest in many applications. ${ }^{46-49}$ NIRCI has the following features: 1) a seamless combination of molecular spectroscopy (chemical) and digital imaging (physical) techniques; 2) a new way to assess sample heterogeneity over a 
<smiles>CC(C)O[C@@H](C)C(=O)CC1CCC(C)C(C)C1</smiles>

PHB

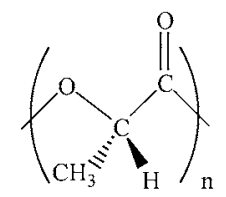

PLLA
Fig. 1 Chemical structures of PHB and PLLA.

range of spatial resolutions; 3) a method that provides distribution information for chemical components in the sample; 4) a solution to some of the limitations of standard instrumental analyses, e.g., spatial information is obtained nondestructively; and 5) a technique that can be used for high throughput chemical analysis (parallel spectroscopic assessment). It is possible to combine NIR spectroscopic information with direct imaging of the spatial distribution of components that make up the blend. In combination with multivariate data analysis, NIRCI provides localized chemical make up of the blend components, as well as the predictions of the blend compositions.

The unique capability of NIRCI to provide both qualitative and quantitative analysis of localized and space-averaged chemical compositions is especially attractive. For example, NIRCI techniques are already used in pharmaceutical applications to reveal the extent of ingredient blending, particle size distribution, the presence of polymorphs, and trace contaminants. To our knowledge, surprisingly little study has yet been carried out on the evaluation of polymer blends by using NIRCI. In the present study, four kinds of PHB/PLLA blends with the PLLA content ranging from 20 to $80 \mathrm{wt} \%$ have been investigated by using NIRCI to elucidate the blend quality of PHB/PLLA blends. This study highlights the potential of NIRCI for qualitative and quantitative nondestructive evaluation of blend homogeneity.

\section{Experimental}

\section{Preparation of blends}

The chemical structures of PHB and PLLA are shown in Fig. 1. PHB $\left(M_{\mathrm{w}}=600000 \mathrm{~g} \mathrm{~mol}^{-1}, M_{\mathrm{w}} / M_{\mathrm{n}}=2.2\right)$ and PLLA $\left(M_{\mathrm{w}}=\right.$ $150000 \mathrm{~g} \mathrm{~mol}^{-1}, M_{\mathrm{w}} / M_{\mathrm{n}}=1.8$ ) were obtained, respectively, from the Procter \& Gamble Company and Shimadzu Corporation (LACTY5000). Blends of PHB and PLLA were prepared by dissolving each component together in hot chloroform. PHB/PLLA blend films were cast on an aluminum dish from $c a$. $1 \mathrm{wt} \%$ chloroform solutions. The concentration of the 40/60 blend solution was slightly higher than those of other blend solutions because of the evaporation of the chloroform solvent. Therefore, when the cast films were prepared, the evaporation speeds of the chloroform from the films were different. To evaporate the solvent completely, we kept the films at $60^{\circ} \mathrm{C}$ in a vacuum-dried oven for $12 \mathrm{~h}$ and then cooled them down to room temperature. Blending ratios were 80/20, 60/40, 40/60, and $20 / 80$ by weight.

\section{Near infrared chemical imaging (NIRCI)}

The Malvern Instruments Ltd. Sapphire Chemical Imaging system consists of a liquid crystal tunable filter, a $320 \times 256$ pixel indium antimony (InSb) focal plane array detection system. The system includes an appropriate optics to preferentially capture diffusely reflected light from each specimen, while minimizing background specular reflection off
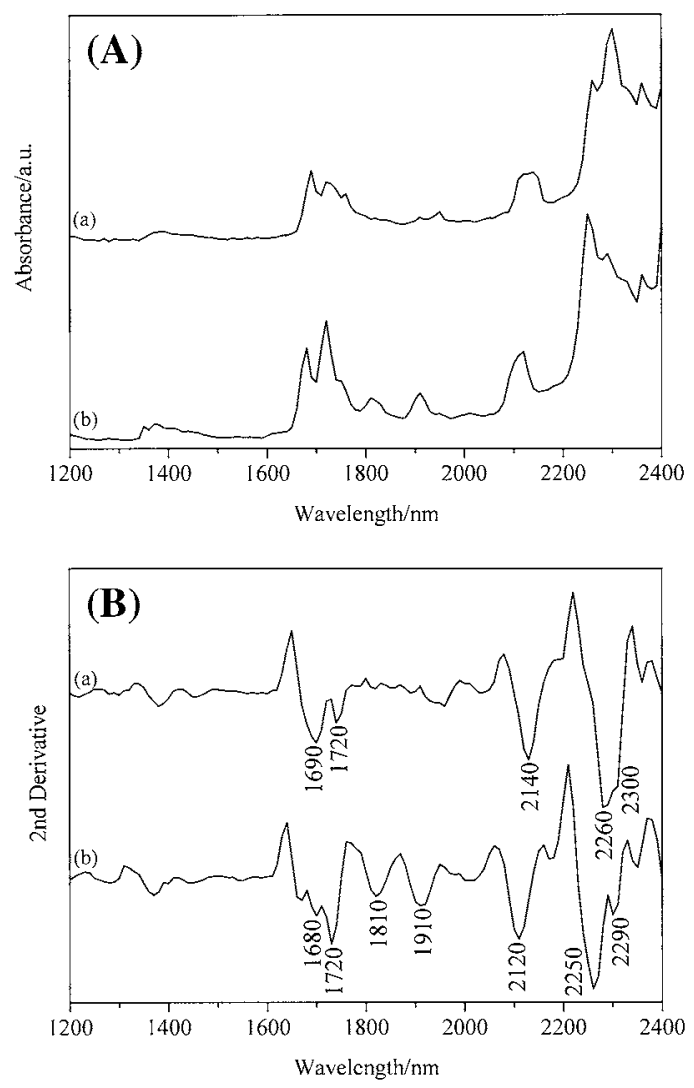

Fig. 2 (A) Raw NIR spectra and (B) the second derivative spectra of neat PHB and PLLA. (a) PHB, (b) PLLA.

of the polished mounting plate. Four tungsten source lamps illuminate the imaging target field. The NIRCI data of the diffuse reflection spectra were collected at $10 \mu \mathrm{m}$ intervals in the $1200-2400 \mathrm{~nm}$ region. The spacial resolution of NIRCI data is $10 \mu \mathrm{m} /$ pixel, so the field of view was $3.2 \times 2.5 \mathrm{~mm}$. Image acquisition time is approximately $3 \mathrm{~min}$.

\section{Data manipulation}

ISys Chemical Imaging Software that was provided by Malvern Instruments Ltd. enables the simultaneous manipulation of spectra of 81920 pixels from a single field of view. The second derivative spectra were calculated from the original NIRCI data before proceeding with further data analyses. The concentration of the blend components were estimated by using the partial least square regression (PLSR) technique. No concentration standards are required for this experiment, as the pure component spectra are all known. Each pure component spectrum from a chemical constituent is defined as a distinct class in the spectral library. All values are derived directly from the NIRCI data of the blends. The resulting PLSR model produces a classification score that varies between 0 and 1 .

\section{Results and Discussion}

\section{NIR spectra of neat PHB and PLLA}

Figures $2 \mathrm{~A}$ and $2 \mathrm{~B}$ show, respectively, the raw NIR spectra and second derivative spectra of neat PHB and PLLA in the $1200-2400 \mathrm{~nm}$ region. The bands due to the combination and first overtone bands of the $\mathrm{CH}$ stretching vibrations and that of 

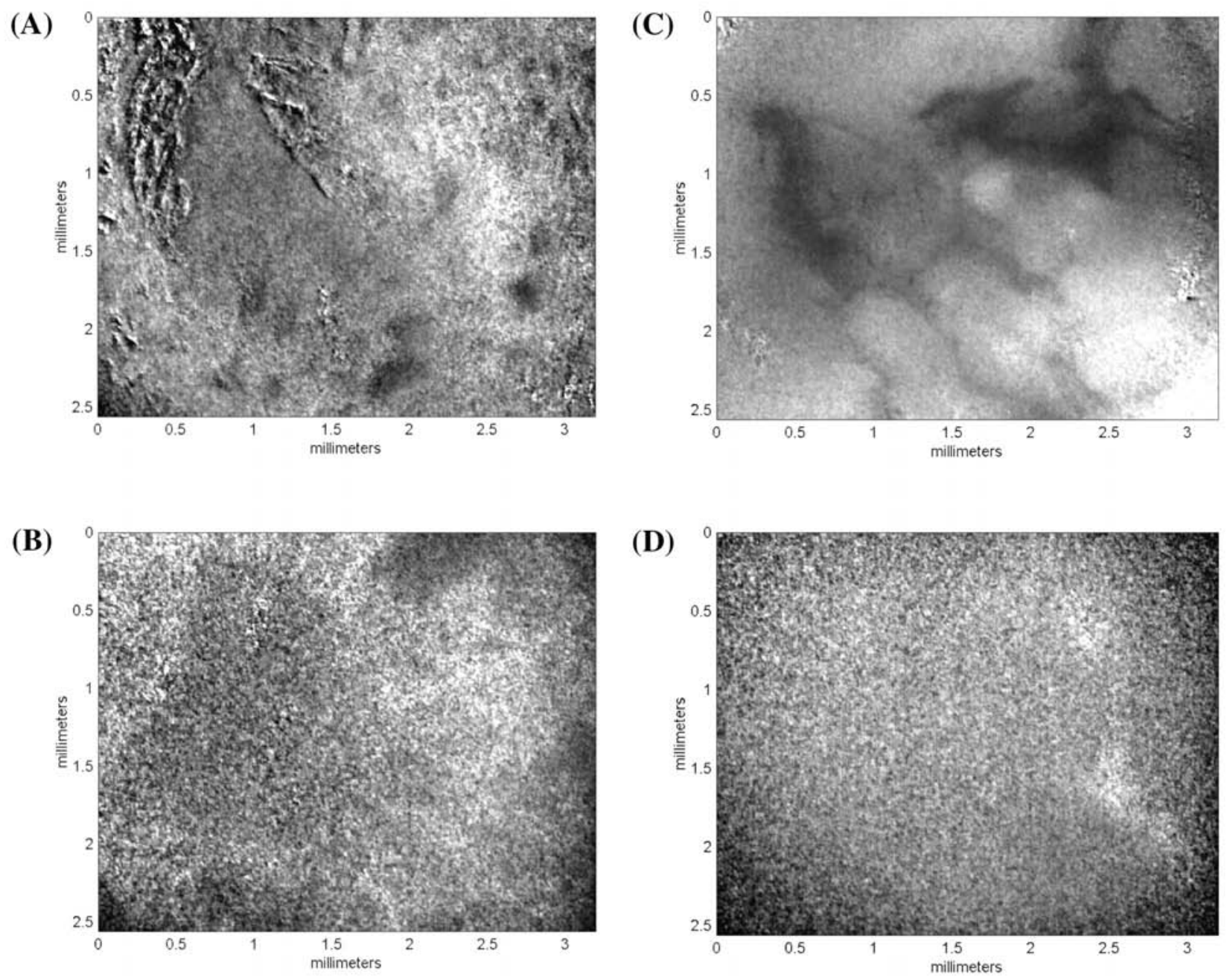

Fig. 3 Score images of PHB/PLLA blends derived from PLSR. PHB/PLLA: (A) 80/20, (B) 60/40, (C) 40/60, (D) 20/80.

Table 1 Wavelength and assignments of NIR bands of PHB and PLLA

\begin{tabular}{|c|c|c|}
\hline $\begin{array}{l}\text { Wavelength/ } \\
\text { nm }\end{array}$ & PHB & PLLA \\
\hline 1690 & $\begin{array}{l}\mathrm{CH}_{3} \text { stretching first } \\
\text { overtone }\end{array}$ & $\begin{array}{l}\mathrm{CH}_{3} \text { stretching first } \\
\text { overtone }\end{array}$ \\
\hline 1720 & $\begin{array}{l}\mathrm{CH}_{3} \text { stretching first } \\
\text { overtone }\end{array}$ & $\begin{array}{l}\mathrm{CH}_{3} \text { stretching first } \\
\text { overtone }\end{array}$ \\
\hline 1820 & & $\begin{array}{l}\mathrm{CH} \text { stretching first } \\
\text { overtone }\end{array}$ \\
\hline 1910 & & $\begin{array}{l}\mathrm{C}=\mathrm{O} \text { stretching second } \\
\text { overtone }\end{array}$ \\
\hline 1950 & $\begin{array}{l}\mathrm{C}=\mathrm{O} \text { stretching second } \\
\text { overtone }\end{array}$ & \\
\hline 2120 & $\begin{array}{l}\mathrm{C}=\mathrm{O} \text { stretching }+\mathrm{CH}_{3} \\
\text { stretching combination }\end{array}$ & \\
\hline 2140 & & $\begin{array}{l}\mathrm{C}=\mathrm{O} \text { stretching }+\mathrm{CH}_{3} \\
\text { stretching combination }\end{array}$ \\
\hline 2250 & & $\begin{array}{l}\mathrm{CH}_{3} \text { stretching }+\mathrm{CH} \\
\text { deformation combination }\end{array}$ \\
\hline 2260 & $\begin{array}{l}\mathrm{CH}_{3} \text { stretching }+\mathrm{CH} \\
\text { deformation combination }\end{array}$ & \\
\hline 2290 & & $\begin{array}{l}\mathrm{CH}_{2} \text { stretching }+\mathrm{CH} \\
\text { deformation combination }\end{array}$ \\
\hline 2300 & $\begin{array}{l}\mathrm{CH}_{2} \text { stretching }+\mathrm{CH} \\
\text { deformation combination }\end{array}$ & \\
\hline
\end{tabular}

the second overtone of the $\mathrm{C}=\mathrm{O}$ stretching vibration appeared in both PHB and PLLA spectra. Assignments of NIR bands of PHB and PLLA are listed in Table 1. Although the only difference in the chemical structure of PHB and PLLA is the number of carbon atoms in the main chain, the intensities of some bands substantially differ from each other. The spectral differences between PHB and PLLA are more clearly seen in the second derivative spectra. However, the bands of PHB and PLLA are still somewhat overlapped, even in the second derivative spectra. Thus, it is difficult to perform the evaluation of the distribution and prediction for the blend components by simply using the intensity at a fixed wavelength. Consequently, multivariate analysis is adopted for NIRCI data.

\section{Evaluation of homogeneity using statistical analysis}

NIRCI nondestructively generates a very large number (81920) of spatially resolved NIR spectra in a few minutes. The spectral data can be decomposed into a set of a small number of classification scores by PLSR. The scores of PLSR are including the information of both the spectral variable and the response variable (the blending ratio). Therefore, we can obtain the PLSR results having the correlation of both variables. Figures $3 A-3 D$ show the score images derived from PHB component class. In the score images, the pixels with higher and lower score values are indicated by white and dark colors, respectively. The color in the most region of the score images 

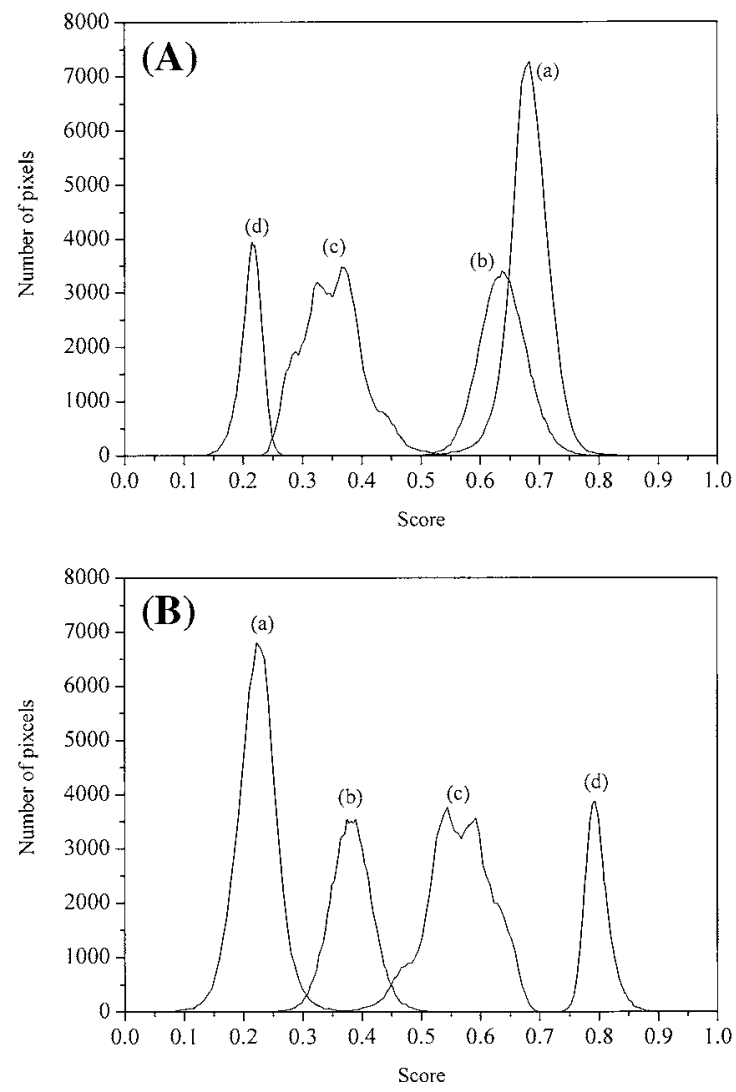

Fig. 4 Histograms derived from the score images for (A) class 1 (PHB) and (B) class 2 (PLLA). PHB/PLLA: (a) 80/20, (b) 60/40, (c) $40 / 60$, (d) $20 / 80$.

is gray, the intermediate color between white and dark colors. On the other hand, the score images associated with PLLA component classes are also gray in the large parts of the score images, although the colors of white and black are indicated inversely in the score images between PHB and PLLA components. The predominantly gray score images indicate that the blends are relatively homogeneous. However, it is hard to discuss the quantitative degree of the homogeneity of these score images.

A histogram for the distribution of intensities (score values) in the score image, which includes some statistical information, is a powerful evaluation tool. A well-mixed blend sample shows a normal distribution. Standard deviation (STD) is one of the useful parameters indicating the overall sample homogeneity and heterogeneity. The more heterogeneous the chemical distribution is, the larger the STD becomes. The STD is often more important in the analysis of a relatively homogeneous sample, instead of an obviously heterogeneous sample, as an indicator of subtle differences in the sample heterogeneity. Figures 4A and 4B, respectively, are the histograms of the score images for PHB and PLLA components in the blends. The STD values of the histogram are summarized in Table 2. As can be seen in Figs. 4A and 4B and in Table 2, these histograms show the near normal distribution except for the $40 / 60$ blend. The chloroform solution of the 40/60 blend had a higher concentration than those of other blends, so the evaporation rate of the chloroform solvent from the cast film might have been different from that from other blends. Thus, the homogeneity of the 40/60 blend may also differ from those of other blends.

The histograms of all the blends show relatively small STD
Table 2 STD values of the histogram for the score images of the blends

\begin{tabular}{ccc}
\hline PHB/PLLA & PHB & PLLA \\
\hline $80 / 20$ & 3.156 & 3.236 \\
$60 / 40$ & 3.868 & 3.391 \\
$40 / 60$ & 4.941 & 5.270 \\
$20 / 80$ & 1.795 & 1.956 \\
\hline
\end{tabular}

Table 3 Predicted values of PHB and PLLA components in the blends

\begin{tabular}{ccc}
\hline PHB/PLLA & PHB, $\%$ & PLLA, $\%$ \\
\hline $80 / 20$ & 75.21 & 24.78 \\
$60 / 40$ & 62.56 & 37.45 \\
$40 / 60$ & 38.31 & 61.67 \\
$20 / 80$ & 21.18 & 78.82 \\
\hline
\end{tabular}

values. Our previous microspectroscopic studies showed the $20 / 80$ blend is the most homogeneous one among all the blends. ${ }^{29,30}$ As expected, the STD of the 20/80 blend shows an especially small value for both components classified to PHB and PLLA, respectively. Thus, it was shown that the score images and their histograms for PHB and PLLA classes together provide the complementary qualitative and quantitative results, indicating that the PHB/PLLA blends studied have a high degree of homogeneity. Since the samples were prepared from cast films, the domains for each blend component are dispersed as smaller crystallized or amorphous particles. The interfacial energy between PHB and PLLA may be so small that they make extremely fine dispersions within each other.

\section{Prediction of the blend components in the blends}

Further quantitative results can be obtained from PLSR analysis. ISys software allows one to define groups or classes of spectra to be used in a reference library, and one can perform PLSR calculations in both classification and concentration modes. In the case of the classification mode, each library class is assumed to be pure component spectra from one chemical component and is automatically assigned a concentration of 1.0. The resulting PLSR model produces a classification "score" that (optimally) varies between 0 and 1 . On the other hand, the concentration mode requires the spectra with various concentrations of the blending components. No calibration data sets are needed for the prediction in NIRCI data analysis, if the NIR data of the neat components are available for the quantitative analysis in classification mode. The predicted values of the spatially averaged contents of PHB and PLLA in the blends derived from PLSR that create the score images shown in Figs. 3A-3D are summarized in Table 3. These predicted values are surprisingly close to those of the actual polymer contents. The small errors of the prediction are explained by the homogeneity of blends indicated by the STD values summarized in Table 2 . The STD values of the score image histogram are the same as the standard errors of prediction (SEP) for the response variable in the result of ISys software. Therefore, if the values of STD are not so large, NIRCI can give us reasonably quantitative results with small standard errors of prediction. 


\section{Conclusion}

In this study, the blend homogeneity of PHB/PLLA blends was investigated by using NIRCI combined with multivariate data analysis. The following conclusions can be reached from the present study. The homogeneities of PHB/PLLA blends are revealed by both qualitative and quantitative analysis. The score images directly depict the spatial distribution of blend components. The histograms of the intensities in the score images show the statistical measure of the blend homogeneity. The small STD values obtained from the histograms indicate that highly homogeneous blends are created by mixing PHB and PLLA. The concentration of the chloroform solution preparing the cast film was low, so the blend components were well dispersed in the chloroform solution. Because of that, the blend components were homogeneous in the cast films. The predicted concentrations of the blend components averaged over the space are close to the actual contents. The STD values indicating the breadth of spatial concentration distribution are not so large for any of the samples studied, so the prediction for the overall blend components can be performed with high precision.

\section{Acknowledgements}

This work was partially supported by an "Open Research Center" project for private universities: matching fund subsidy from MEXT (Ministry of Education, Culture, Sports, Science and Technology), $2001-2005$. This work was also supported by Kwansei-Gakuin University "Special Research" project, $2004-2008$

\section{References}

1. Y. Doi, "Microbial Polyesters", 1990, VCH Publishers, New York.

2. M. M. Satkowski, D. H. Melik, J. P. Autran, P. R. Green, I. Noda, and L. A. Schechtman, "Biopolymers", ed. A. Steinbüchel and Y. Doi, 2001, Wiley-VCH, Wienheim, 231.

3. C. Bastioli, "Handbook of Biodegradable Polymers", 2005, Rapra Technology Limited, UK.

4. G. Kobayashi, T. Shiotani, Y. Shima, and Y. Doi, "Biodegradable Plastics and Polymers", ed. Y. Doi and K. Fukuda, 1994, Elsevier, Amsterdam, 410.

5. A. J. Anderson and E. A. Dawes, Microbiol. Rev., 1990, 54 450

6. M. Vert, Biomacromolecules, 2005, 6, 538 .

7. T. Iwata and Y. Doi, Macromol. Chem. Phys., 1999, 200, 2429.

8. H. Tsuji, "Biopolymers", ed. A. Steinbüchel and Y. Doi, 2002, Wiley-VCH, Wienheim, 129.

9. J. R. Dorgan, "Poly(lactic acid) Properties and Prospects of an Environmentally Benign Plastic", 1999, American Chemical Society: Washington, D.C., 145.

10. Y. Ikada and H. Tsuji, Macromol. Rapid Commun., 2000 , $21,117$.

11. H. Urayama, T. Kanamori, and Y. Kimura, Macromol. Mater. Eng., 2002, 287, 116.

12. M. Yokouchi, Y. Chatani, H. Tadokoro, K. Teranishi, and H. Tani, Polymer, 1973, 14, 267.

13. K. Okamura and R. H. Marchessault, in "Conformation of Biopolymers", ed. G. N. Ramachandran, 1967, Vol. 2,
Academic Press, New York, 709

14. W. Hoogsteen, A. R. Postema, A. J. Pennings, G. ten Brinke, and P. Zugenmaier, Macromolecules, 1990, 23, 634.

15. P. De Santis and A. J. Kovacs, Biopolymers, 1968, 6, 299.

16. J. Kobayashi, T. Asahi, M. Ichiki, A. Okikawa, H. Suzuki, T. Watanabe, E. Fukada, and Y. Shikinami, J. Appl. Phys., 1995, 77, 2957.

17. H. Sato, J. Dybal, R. Murakami, I. Noda, and Y. Ozaki, J. Mol. Struct., 2005, 744 - 747, 35.

18. H. Sato, R. Murakami, A. Padermshoke, F. Hirose, K. Senda, I. Noda, and Y. Ozaki, Macromolecules, 2004, 37, 7203.

19. H. Sato, K. Mori, R. Murakami, Y. Ando, I. Takahashi, J. Zhang, H. Terauchi, F. Hirose, K. Senda, K. Tashiro, I. Noda, and Y. Ozaki, Macromolecules, 2006, 39, 1525.

20. J. Zhang, H. Tsuji, I. Noda, and Y. Ozaki, J. Phys. Chem. $B, 2004,108,11514$

21. J. Zhang, H. Sato, H. Tsuji, I. Noda, and Y. Ozaki, J. Mol. Struct., 2005, 735 - 736, 249.

22. J. Zhang, Y. Duan, H. Sato, H. Tsuji, I. Noda, S. Yan, and Y. Ozaki, Macromolecules, 2005, 38, 8012.

23. M. Gazzano, M. L. Focarete, C. Riekel, and M. Scandola, Biomacromolecules, 2004, 5, 553.

24. I. Ohkoshi, H. Abe, and Y. Doi, Polymer, 2000, 41, 5985.

25. E. Blümm and A. J. Owen, Polymer, 1995, 36, 4077.

26. N. Koyama and Y. Doi, Polymer, 1997, 38, 1589.

27. J. W. Park, Y. Doi, and T. Iwata, Biomacromolecues, 2004, $5,1557$.

28. L. Zhang, C. Xiong, and X. Deng, Polymer, 1996, 37, 235.

29. T. Furukawa, H. Sato, R. Murakami, J. Zhang, Y. Duan, I. Noda, S. Ochiai, and Y. Ozaki, Macromolecules, 2005, 38, 6445.

30. T. Furukawa, H. Sato, R. Murakami, J. Zhang, I. Noda, S. Ochiai, and Y. Ozaki, Polymers, 2006, 47, 3132.

31. D. A. Burns and E. W. Ciurcziak, "Handbook of NearInfrared Analysis", 2004, Marcel Dekker, New York.

32. H. W. Siesler, Y. Ozaki, S. Kawata, and H. M. Heise (ed.), "Near-infrared Spectroscopy", 2002, Wiley-VCH, Weinheim.

33. R. Raghavachari (ed.), "Near-Infrared Applications in Biotechnology", 2001, Marcel Dekker, New York.

34. K. I. Hildrum, T. Isaksson, T. Naes, and A. Tandberg (ed.), "Near Infra-red Spectoscopy: Bridging the Gap between Data Analysis and NIR Applications", 1992, Ellis Horwood, Chichester.

35. K. R. Beebe, R. J. Pell, and M. B. Seasholtz, "Chemometrics: A Practical Guide", 1998, John Wiley and Sons, New York.

36. H. Martens and T. Næs, "Multivariate Calibration", 1989, John Wiley and Sons, Chichester.

37. T. Næs, T. Isaksson, T. Fearn, and T. Davies, "A UserFriendly Guide to Multivariate Calibration and Classification", 2002, NIR Publications, Chichester.

38. B. G. M. Vandeginste, D. L. Massart, L. M. C. Buydens, S. De Jong, P. J. Lewi, and J. Smeyers-Verbeke, "Handbook of Chemometrics and Qualimetrics: Part B", 1998, Elsevier, Amsterdam.

39. Y. Hu, J. Zhang, H. Sato, Y. Futami, I. Noda, and Y. Ozaki, Macromolecules, 2006, 39, 3841.

40. M. Watari, H. Higashiyama, N. Mitsui, M. Tomo, and Y. Ozaki, Appl. Spectrosc., 2004, 58, 248.

41. M. Watari and Y. Ozaki, Appl. Spectrosc., 2004, 58, 1210.

42. M. Watari and Y. Ozaki, Appl. Spectrosc., 2005, 59, 60.

43. M. Watari and Y. Ozaki, Appl. Spectrosc., 2006, 60, 529. 
44. T. Furukawa, Y. Kita, S. Sasao, K. Matsukawa, M. Watari, S. Šašić, H. W. Siesler, and Y. Ozaki, J. Near Infrared Spectrosc., 2002, 10, 195.

45. Šsăić, Y. Kita, T. Furukawa, M. Watari, H. W. Siesler, and Y. Ozaki, Analyst, 2000, 125, 2315.

46. E. N. Lewis, L. H. Kidder, E. Lee, and K. S. Haber, "Spectrochemical Analysis Using Infrared Multichannel Detectors", ed. R. Bhargava and I. W. Levin, 2005,
Blackwell Publishing Ltd., Oxford, 25.

47. V. W. Smail, A. K. Fritz, and D. L. Wetzel, Vib. Spectrosc., 2006, 42, 215.

48. M. Politi and C. D. Tran, J. Non-Cryst. Solids, 2002, 304, 64.

49. E. Lee, L. H. Kidder, V. F. Kalasinsky, J. W. Schoppelrei, and E. N. Lewis, Cytometry A, 2006, 69A, 888. 